\title{
ColN: co-inducible nitrate expression system for secondary metabolites in Aspergillus nidulans
}

\author{
Philipp Wiemann ${ }^{1,3+}$ (D), Alexandra A. Soukup ${ }^{1,4+}$, Jacob S. Folz ${ }^{1,5}$, Pin-Mei Wang ${ }^{1,6}$, Andreas Noack \\ and Nancy P. Keller ${ }^{1,2^{*}}$ (D)
}

\begin{abstract}
Background: Sequencing of fungal species has demonstrated the existence of thousands of putative secondary metabolite gene clusters, the majority of them harboring a unique set of genes thought to participate in production of distinct small molecules. Despite the ready identification of key enzymes and potential cluster genes by bioinformatics techniques in sequenced genomes, the expression and identification of fungal secondary metabolites in the native host is often hampered as the genes might not be expressed under laboratory conditions and the species might not be amenable to genetic manipulation. To overcome these restrictions, we developed an inducible expression system in the genetic model Aspergillus nidulans.

Results: We genetically engineered a strain of A. nidulans devoid of producing eight of the most abundant endogenous secondary metabolites to express the sterigmatocystin $\mathrm{Zn}(\mathrm{II})_{2} \mathrm{Cys}_{6}$ transcription factor-encoding gene aflR and its cofactor aflS under control of the nitrate inducible niiA/niaD promoter. Furthermore, we identified a subset of promoters from the sterigmatocystin gene cluster that are under nitrate-inducible AfR/S control in our production strain in order to yield coordinated expression without the risks from reusing a single inducible promoter. As proof of concept, we used this system to produce $\beta$-carotene from the carotenoid gene cluster of Fusarium fujikuroi.
\end{abstract}

Conclusion: Utilizing one-step yeast recombinational cloning, we developed an inducible expression system in the genetic model A. nidulans and show that it can be successfully used to produce commercially valuable metabolites.

Keywords: Yeast recombinational cloning, Secondary metabolism, Genetic engineering, Carotenes, Aspergillus nidulans, Fusarium fujikuroi, AflR, Sterigmatocystin, Nitrate, Biotechnology, Synthetic biology

\section{Background}

Natural products or secondary metabolites (SMs) have been invaluable as platforms for developing front-line drugs. Between 1981 and 2010, 5\% of the 1031 new chemical entities approved as drugs by the Food and Drug Administration (FDA) were natural products or derivatives, including $48.6 \%$ of cancer medications [36]. In addition, SMs are major sources of innovative

\footnotetext{
*Correspondence: npkeller@wisc.edu

'Philipp Wiemann and Alexandra A. Soukup contributed equally to this work

1 Department of Medical Microbiology and Immunology, University of Wisconsin, Madison, WI 53706, USA

Full list of author information is available at the end of the article
}

therapeutic agents for both bacterial and fungal infectious diseases, lipid disorders, and immunomodulation [16]. Fungal SMs have proven to be a particularly important source of new leads with useful pharmaceutical activities. A literature survey of fungal metabolites, covering 1500 fungal SMs that were isolated and characterized between 1993 and 2001, showed that more than half of the molecules had antibacterial, antifungal or antitumor activity [41]. However, the full metabolic potential of the majority of existing fungal species has not been investigated. Major roadblocks in this endeavor are that some species are not cultivable under laboratory conditions and/or their SM gene clusters are silent. Previous strategies on activating fungal SMs have focused mainly on (1) 
activating endogenous gene clusters by over-expressing the pathway-specific transcription factor [13, 43, 54]), (2) manipulating global regulators $[11,28]$, and (3) expressing the entire gene cluster in a heterologous host [8]. Although successful in some cases, these strategies have significant disadvantages. As not all fungal species are easily amenable to genetic manipulation, strategies that focus on endogenous activation are impossible in these species. This prevents the option of over-expressing a cluster-specific transcription factor, which has been the most successful approach to activating cryptic clusters thus far (reviewed in [51]). In addition, not all SM clusters contain transcription factors and although some clusters have been activated by overexpressing every gene in the cluster $[14,53]$, this adds labor and time to the process and may be hard to achieve with clusters containing many genes.

Previous approaches expressing fungal gene clusters in heterologous hosts (mainly Saccharomyces cerevisiae or Aspergillus spp.) focused on amplification of the entire gene cluster including native promoters. Although these approaches lead to expression of the targeted gene clusters in some cases [55], the use of native promoters cannot guarantee controlled activation of the genes. Therefore, the identification and use of defined promoters presents an alternative means to activate clusters. Cloning of entire gene clusters can be achieved by PCR-based amplification of the desired DNA region and subsequent yeast recombination-based cloning [55]. Promoter exchanges using this technique rely on the identification of different promoter regions as the use of identical promoter sequences is impossible due to the homologous recombination among promoters [14].

Our goal was to identify a series of distinct promoters that could be activated in one step and, furthermore, activated under an inducible system as many SMs exhibit antifungal properties that could be toxic to the heterologous host $[12,46]$. Thus, we designed a strain of genetic model organism Aspergillus nidulans that contains an inducible genetic construct which allows for expression of the positive acting transcriptional elements of the sterigmatocystin (ST) gene cluster, aflR and aflS (formerly aflJ, [20]). The ST gene cluster contains 25 distinct genes and it is known that the transcription factor AflR and its cofactor AflS are responsible for ST production [9]. We constructed a strain of $A$. nidulans with its endogenous ST cluster removed but with aflR/aflS placed back into the strain under the control of a nitrate inducible divergent promoter $(n i i A(\mathrm{p}) / n i a D(\mathrm{p}))[44,45]$, thereby allowing controlled aflR/aflS expression based on culture conditions. We tested the expression of all 25 ST promoters by AflR/AflS in this strain and identified eight ST promoters specifically regulated by nitrate induction of aflR/S. To test the system for expression of a fungal secondary metabolite, we cloned the carotenoid gene cluster from Fusarium fujikuroi and placed it under control of these inducible ST promoters. We show that the derived $A$. nidulans transformants produce $\beta$-carotene in competitive levels to existing systems using our technology.

\section{Methods}

\section{Fungal strains and culture conditions}

Aspergillus nidulans strains used in this study are listed in Additional file 1: Table S1. Fusarium fujikuroi IMI58289 [51] was used for carRA, carB, and ggs1 amplification as a reference for carotenoid production. Strains were maintained as glycerol stocks and activated on solid glucose minimal medium (GMM) at $37^{\circ} \mathrm{C}$ with appropriate supplements [48]. For experiments in Fig. 1, nitrate was replaced with equimolar ammonium tartrate and
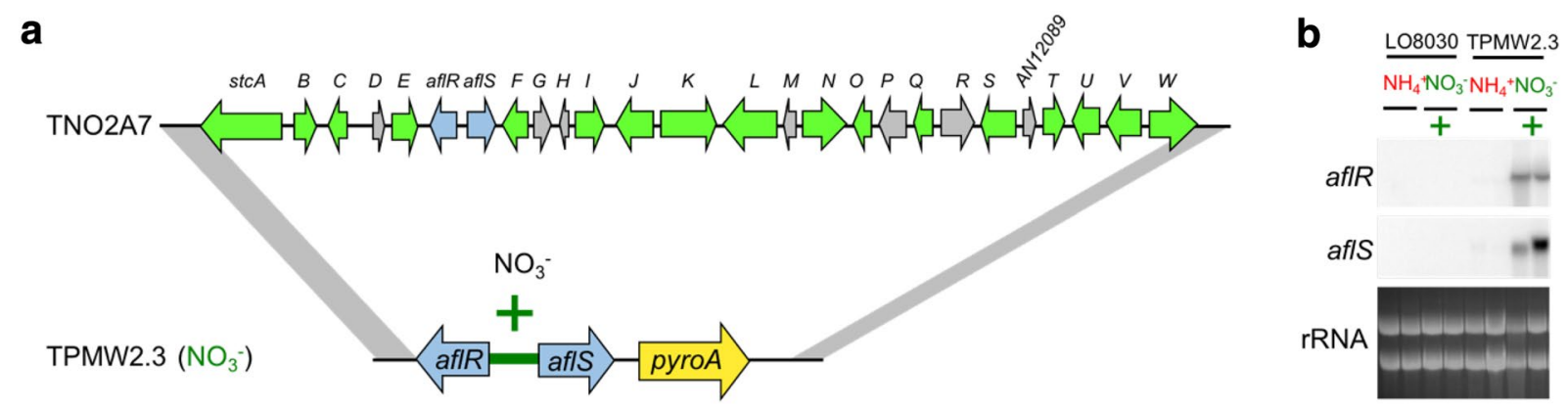

Fig. 1 Nitrate-inducible aflR/S expression in A. nidulans. a Schematic overview of the aflR/S expression strain TPMW2.3 that harbors the nitrateinducible niaD/niiA promoter-driven aflR/S genes at the native sterigmatocystin cluster locus. b Northern blot analysis of nitrate-dependent affR/S expression in A. nidulans TPMW2.3. Strains were grown in $50 \mathrm{~mL}$ of GMM with $35 \mathrm{mM}$ glutamine as nitrogen source supplemented with $5 \mathrm{mM}$ uracil/uridine and riboflavin for $24 \mathrm{~h}$ at $250 \mathrm{rpm}$ at $37^{\circ} \mathrm{C}$. The mycelia were washed and shifted into new media containing either $\mathrm{NH}_{4}{ }^{+}$or $\mathrm{NO}_{3}{ }^{-}$as nitrogen sources plus supplements and grown at $250 \mathrm{rpm}$ and $37^{\circ} \mathrm{C}$ for $1 \mathrm{~h}$ before RNA extraction. Strains were grown in duplicate, indicated genes were probed and rRNA was visualized as loading control 
supplemented with $5 \mathrm{mM}$ uracil and uridine, respectively. For solidified media, Noble Agar (Difco ${ }^{\mathrm{TM}}, \mathrm{BD}$, USA) was added at $16 \mathrm{~g} / \mathrm{L}$. For pyrG auxotrophs, the growth medium was supplemented with $5 \mathrm{mM}$ uridine and uracil. For riboB auxotrophs, the growth medium was supplemented with $5 \mathrm{mM}$ riboflavin. For pyro $A$ auxotrophs, the growth medium was supplemented with $5 \mathrm{mM}$ pyridoxine. Conidia were harvested in $0.01 \%$ Tween 80 and enumerated using a hemocytometer. For RNA analysis, indicated strains were inoculated into $50 \mathrm{~mL}$ of liquid GMM with $35 \mathrm{mM}$ glutamine as nitrogen source at $5 \times 10^{6}$ conidia $/ \mathrm{mL}$ in duplicate and grown at $37^{\circ} \mathrm{C}$ and $250 \mathrm{rpm}$ for $24 \mathrm{~h}$ in ambient light conditions. The cultures were shifted into new GMM media either containing $70 \mathrm{mM}$ nitrate or $35 \mathrm{mM}$ glutamine as nitrogen source for $1 \mathrm{~h}$. The mycelium was harvested and lyophilized before RNA extraction. For carotenoid production $5 \times 10^{6}$ conidia of indicated strains were inoculated on $20 \mathrm{~mL}$ liquid stationary GMM with either containing $70 \mathrm{mM}$ nitrate or $35 \mathrm{mM}$ glutamine as nitrogen source for 3 days at $37^{\circ} \mathrm{C}$ (A. nidulans) or $29^{\circ} \mathrm{C}$ (F. fujikuroi) in the dark. To distinguish between carotenoid production in the mycelia and spores, the strains were grown on liquid stationary GMM media (described above) for 3 days at $37{ }^{\circ} \mathrm{C}$ in the light to induce sporulation. Mycelia and spores were resuspended in $0.01 \%(\mathrm{v} / \mathrm{v})$ Tween 80 , vortexed to separate spores from mycelia. Spores were separated from mycelia by filtration.

\section{Yeast recombinational cloning}

Yeast strain BJ5464 (MATalpha, ura3-52, trp1, leu2- $\Delta 1$, his3- $\triangle 200$, pep 4::HIS3, prb1- $\triangle 1.6 R$, can1, GAL) was inoculated into $25-50 \mathrm{~mL}$ of appropriate media ( $2 \times$ YPDA) and incubated at $30{ }^{\circ} \mathrm{C}$ at $200 \mathrm{rpm}$ overnight. The concentration of overnight culture was determined using OD 600 with a $1 \times 10^{7}$ cells $/ \mathrm{mL}$ set to an OD reading of 1.0. Then, $1.25 \times 10^{9}$ cells were centrifuged at $3000 \times g$ for $5 \mathrm{~min}$. Fresh media was added to the pelleted cells and added to a baffled flask containing $250 \mathrm{~mL}$ of $2 \times$ YPAD to a final concentration of $5 \times 10^{6}$ cells $/ \mathrm{mL}$ and incubated at $30{ }^{\circ} \mathrm{C}$ at $200 \mathrm{rpm}$ until the cell titer reached $2 \times 10^{7}$ cells $/ \mathrm{mL}$. Cells were harvested by centrifugation at $3000 \times g$ for $5 \mathrm{~min}$. Supernatant was removed and the cells were washed with double distilled $\mathrm{H}_{2} \mathrm{O}\left(\mathrm{ddH}_{2} \mathrm{O}\right)$. The cells were transferred to one $50 \mathrm{~mL}$ falcon tube and washed an additional time with $\mathrm{ddH}_{2} \mathrm{O}$ before they were centrifuged at $3000 \times g$ for $5 \mathrm{~min}$. Cells were resuspended in $5 \%$ glycerol and $10 \%$ DMSO to a final concentration of $2 \times 10^{9}$ cells $/ \mathrm{mL}$ aliquoted in $100 \mu \mathrm{L}$. These cells can be frozen at $-80{ }^{\circ} \mathrm{C}$ for several weeks. Before transformation, cells were pelleted and the supernatant removed. For transformation $250 \mathrm{ng}$ of the digested backbone vector and $500 \mathrm{ng}$ of each DNA PCR product (see below) were added and adjusted to a final volume of $14 \mu \mathrm{L}$ with $\mathrm{ddH}_{2} \mathrm{O}$. The DNA mixture was added to the yeast along with $260 \mu \mathrm{L}$ of a $50 \%(\mathrm{w} / \mathrm{v})$ polyethyleneglycol 3600, $36 \mu \mathrm{L} 1 \mathrm{M}$ lithium acetate and $50 \mu \mathrm{L}$ of denatured sheared salmon sperm DNA $(2 \mathrm{mg} / \mathrm{mL})$. The mixture was vortexed and incubated at $42{ }^{\circ} \mathrm{C}$ for $45 \mathrm{~min}$. Cells were centrifuged at $13,000 \times g$ for $30 \mathrm{~s}$ and the supernatant was removed. The cells were carefully resuspended in $1 \mathrm{~mL}$ $\mathrm{dd}_{2} \mathrm{O}$ and $200-500 \mu \mathrm{L}$ were spread on solidified synthetic drop out media containing all necessary supplements without uracil for selection. Plates were incubated at $30^{\circ} \mathrm{C}$ for $3-5$ days.

\section{Plasmid isolation from yeast}

All colonies from a transformation plate were scraped and incubated overnight in liquid synthetic yeast drop out solution containing the appropriate supplements without uracil at $200 \mathrm{rpm}$ at $30^{\circ} \mathrm{C}$. One $\mathrm{mL}$ was pelleted and the supernatant removed. $200 \mu \mathrm{L}$ of STC buffer (50 mM Tris- $\mathrm{HCl} \mathrm{pH}$ 7.5, 1.2 M sorbitol, $50 \mathrm{mM} \mathrm{CaCl}_{2}$ ) including $3 \mu \mathrm{L}$ Zymolase was added and incubated at $37^{\circ} \mathrm{C}$ for $1 \mathrm{~h}$. To the mixture, $200 \mu \mathrm{L}$ of $1 \%$ (w/v) sodium dodecyl sulfate (SDS) in $200 \mathrm{mM} \mathrm{NaOH}$ were added and inverted. The solution was neutralized by adding $240 \mu \mathrm{L}$ of $3 \mathrm{M}$ potassium acetate, $\mathrm{pH} 5.5$ and inverted. The mixture was centrifuged and the supernatant mixed with $600 \mu \mathrm{L}$ isopropanol, inverted and centrifuged at maximum speed for $10 \mathrm{~min}$. The supernatant was removed and the pellet was washed with $70 \%(\mathrm{v} / \mathrm{v})$ ethanol. The pellet was air dried and resuspended in $30 \mu \mathrm{L} \mathrm{ddH_{2 }} \mathrm{O}$.

\section{Transformation of Escherichia coli and plasmid conformation}

Following standard techniques [23], $10 \mu \mathrm{L}$ of the yeast plasmid extract were transformed into $E$. coli and positive colonies were selected on media containing ampicillin. Plasmids from colonies were isolated using standard procedures [23]. Plasmids were restriction digested with appropriate enzymes to confirm correct insertion. Additional confirmation was achieved using PCR amplification of fused DNA products. To ensure correct DNA sequences for expression plasmids, Sanger sequencing was performed. The correct plasmids were then grown in a $50 \mathrm{~mL}$ culture and plasmids were isolated using the Quantum Prep ${ }^{\circledR}$ Plasmid Midiprep Kit (Biorad) according to the manufacturers' instructions. Before fungal transformation, the plasmids were linearized using $A s c \mathrm{I}$.

\section{Plasmid construction and fungal transformation}

Expression fragments were created by yeast recombinational cloning as described above. All primers used are listed in Additional file 1: Table S2 and all plasmids are listed in Additional file 1: Table S3. For assembling 
the nitrate inducible aflR/S construct, six fragments total were amplified and eventually cloned into the $A s c \mathrm{I}$ digested plasmid backbone of pYHC-yA-riboB [57]. The $3^{\prime}$ flanks of $s t c A$ and stc $W$ were amplified from $A$. nidulans LO8030 DNA using primer pairs $s t c A 3^{\prime}-\mathrm{F} /-\mathrm{R}$ and stc $W 3^{\prime}-\mathrm{F} / \mathrm{R}$ with the $-\mathrm{R}$ primers containing $5^{\prime}$ overlaps to the respective site of $A s c \mathrm{I}$ digested plasmid backbone and the -F primers having overlaps to the aflS terminator and pyro $A$ cassette, respectively. The bidirectional niaD/niiA promoter region was amplified from $A$. nidulans LO8030 $[15,38]$ with overlaps to the open reading frames of aflR and aflS using primer pairs nitrate-F/-R. The open reading frame of aflR including $500 \mathrm{bp}$ of terminator was amplified from $A$. nidulans FGSC 4A DNA using primer pair aflR-F/-R where the $-\mathrm{R}$ primer had a $5^{\prime}$ overhang to the terminator region of the A. fumigatus pyro $A$ gene. The open reading frame of aflS was amplified from $A$. nidulans FGSC 4A DNA using primer pairs aflS-F/-R with the $-\mathrm{R}$ primer having a $5^{\prime}$ overlap to the $-\mathrm{F}$ primer used to amplify the $s t c W$ flank. The pyro $A$ cassette was retrieved through PstI restriction digest of pJMP61 [7]. After yeast recombinational cloning, the plasmid pPMW1 was created. For sterigmatocystin promoter studies the entire bidirectional promoter region between two open reading frames was cloned or, in the case of monodirectional promoters $500 \mathrm{bp}$ upstream of the open reading frame was amplified using primer pairs stc "gene name"-pF/stc "gene name"-pR including $5^{\prime}$ overlaps to the $w A 5^{\prime}$ flank and the open reading frame of $p y r G$ gene from A. fumigatus CEA10. Plasmid pYHC-wA-pyrG [55] was linearized using NheI. After yeast recombineering, plasmid pAN "stcGene" were yielded. For constructing the carotenoid expression plasmid pJSF1, the bidirectional promoter region between $s t c A$ and $s t c B$ was amplified using primer pair stcAB-cF/-cR with overlaps to the carotenoid cluster genes $\operatorname{carR} A$ and $\operatorname{car} B$ from $F$. fujikuro $i$ IMI58289. The open reading frame of carR $A$ including 500 bp terminator region was amplified from $F$. fujikuroi IMI58289 DNA using primer pairs carRA-F/-R with the $-\mathrm{R}$ primer including an overlap to the $w A 3^{\prime}$ flank of plasmid pYHC-wA-pyrG. The open reading frame of $c a r B$ including 500 bp terminator region was amplified from $F$. fujikuroi IMI58289 DNA using primer pairs carB-cF/-cR with the -cR primer including an overlap to the $w A 5^{\prime}$ flank of plasmid pYHC-wA-pyrG. All fragments were assembled using yeast recombinational cloning into EcoRI/XhoI linearized pYHC-wA-pyrG resulting in PJSF1. pJSF2 was assembled in a similar process using EcoRI/XhoI linearized pYHC-yA-riboB and PCR amplicons of the $s t c M$ promoter (amplified with $s t c M-c F /-c R$ ) and $g g s 1$ (amplified with $g g s 1-c F /-c R$ ).

Transformation of $A$. nidulans was performed as previously described [40]. For selection of nitrate inducible
aflR/S strains, $A$. nidulans LO8030 was used as the recipient strain. pPMW1 was linearized using AscI, transformed into LO8030, and transformants were selected on media where pyridoxine was omitted and uracil/uridine and riboflavin were supplemented yielding strain TPMW2.3. For selection of stc promoter test strains, TPMW2.3 was used as the recipient strain. pAN "stcGene" plasmids were linearized using Sbfl and transformants were selected on media were riboflavin was omitted and uracil/uridine was supplemented yielding strains TANx and TAASx (see Additional file 1: Table S1). To create a riboflavin prototrophic strain, TPMW2.3 was transformed with $S b f 1$ linearized pYHC-yA-riboB and selected on media where riboflavin was omitted and uracil/uridine was supplemented yielding strain TPMW7.2. For selection of car expression strains, TPMW7.2 was used as the recipient strain and Sbfl linearized pTJSF1 was transformed into TPMW7.2 and transformants selected on media omitting uracil/uridine yielding strain TJSF1.1. An auxotrophic control strain was generated by using TPMW7.2 as recipient strain and Sbfl linearized pYHC-wA-pyrG was transformed and selected on media without supplements yielding strain TPMW8.2. For DNA isolation, all fungal strains were grown for $24 \mathrm{~h}$ at $37{ }^{\circ} \mathrm{C}$ (Aspergillus) or $29^{\circ} \mathrm{C}$ (Fusarium) in steady state liquid GMM, supplemented appropriately as described by Shimizu and Keller [48]. Single integration was confirmed by Southern analysis as described by [23] using $\mathrm{P}^{32}$-labelled probes created by amplification of the indicated DNA fragment in Additional file 2: Figures S1-S4.

\section{Carotenoid analysis}

Carotenoids were extracted and analyzed as previously described [18, 19]. Briefly, carotenoids were extracted with acetone from freeze dried mycelia and were separated by thin layer chromatography developed in light petroleum/diethyl ether/acetone $(4: 1: 1 ; \mathrm{v} / \mathrm{v} / \mathrm{v})$. The bands were scraped out and dissolved in acetone. Highperformance liquid chromatography (HPLC) was used to analyze the $\beta$-carotene content by comparison to an authentic standard. HPLC separation was performed on using a ZORBAX Eclipse XDB-C18 column (Agilent, $4.6 \mathrm{~mm}$ by $150 \mathrm{~mm}$ with a $5 \mu \mathrm{m}$ particle size) by using a binary gradient of methanol/t-butylmethyl ether (1:1) $(\mathrm{v} / \mathrm{v})$ as solvent $\mathrm{A}$ and methanol/t-butylmethyl ether/ water $(5: 1: 1)(\mathrm{v} / \mathrm{v} / \mathrm{v})$ as solvent $\mathrm{B}$ using a Flexar Binary Liquid Chromatography (LC) Pump (PerkinElmer) coupled to a Flexar LC Autosampler (Perkin Elmer) and a Flexar PDA Plus Detector (PerkinElmer). The binary gradient started with a linear step from $0 \mathrm{~A}$ to $57 \% \mathrm{~A}$ in $45 \mathrm{~min}$ and an additional linear gradient to $100 \% \mathrm{~A}$ in $0.5 \mathrm{~min}$ and hold for $25 \mathrm{~min}$ at a flow rate of $2 \mathrm{~mL} / \mathrm{min}$. Identification and relative quantification of secondary 
metabolites was performed using Chromera Manager (PerkinElmer) by comparison to an authentic standard (Sigma Aldrich).

\section{Results}

The sterigmatocystin (ST) gene cluster of $A$. nidulans is known to harbor 25 genes involved in biosynthesis of sterigmatocystin [9]. While environmental regulation of the ST gene cluster is complex and not well understood, it was the first cluster that identified a gene product encoded within the cluster itself to function as a clusterspecific $\mathrm{Zn}(\mathrm{II})_{2} \mathrm{Cys}_{6}$ transcription factor, called AflR [21]. The gene encoding AflR shares a bidirectional promoter with aflS encoding a transcriptional cofactor of AflR [20]. We replaced the native promoter of $a f l R / S$ with the well characterized niaD/niiA promoter which is induced by the presence of nitrate in the absence of other nitrogen sources [10]. We confirmed nitrate-dependent expression of aflR/S by northern blot analysis (Fig. 1b).
Next, we set out to test which of the 25 stc gene promoters would be nitrate-inducible in our production strain (TPMW2.3). Since TPMW2.3 is a uracil/uridine and riboflavin auxotroph, we designed plasmids that contain each of the $25 \mathrm{stc}$ gene promoters, respectively, driving expression of the A. fumigatus pyrG gene along with a riboB selectable marker flanked by bordering regions of the $y A$ locus (Fig. 2a; Additional file 1: Table S3; Additional file 2: Fig. S2). Using a minimalized promoter selection strategy, we chose promoter regions as follows: For unidirectional stc genes, the promoter region was amplified from the first base after the stop codon of the first gene to the start codon of the second gene, but not exceeding $1 \mathrm{~kb}$. In cases of bidirectional promoters, the entire region between the two start codons was chosen, not exceeding $1 \mathrm{~kb}$. We selected 25 strains for each stc promoter for riboflavin prototrophy, exhibiting yellow spore color, and a control strain that did not include a stc promoter. To test for the ability of AflR/S to induce AfpyrG expression driven by each of the stc a

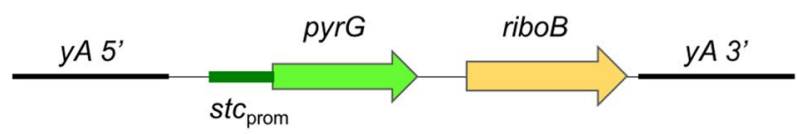

b

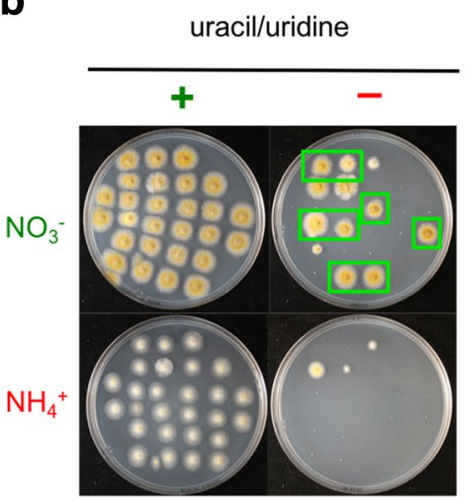

C

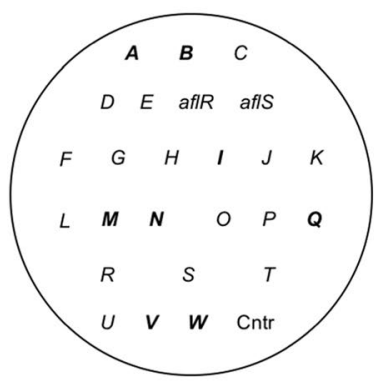

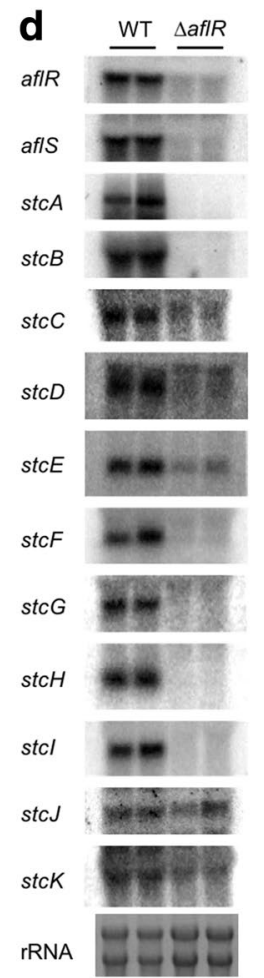

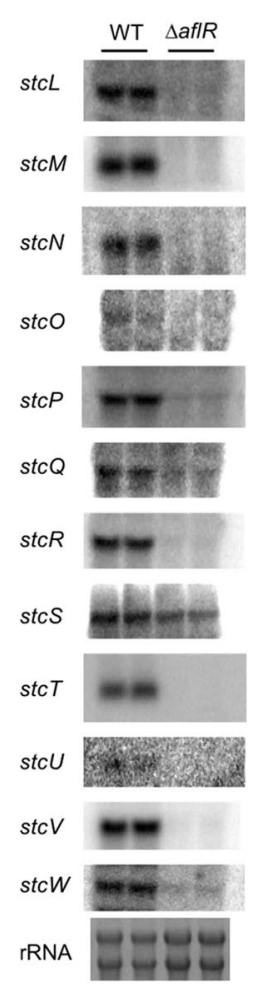

Fig. 2 Nitrate- and stc promoter-dependent pyrG expression. a Schematic overview of A. niduans stc promoter driven pyrG test strains integrated at the $y A$ locus. b A. nidulans strains were grown for $72 \mathrm{~h}$ at $37^{\circ} \mathrm{C}$ on solidified GMM plates containing $\mathrm{NH}_{4}{ }^{+}$or $\mathrm{NO}_{3}^{-}$as nitrogen and half of the plates were supplemented with $5 \mathrm{mM}$ uracil/uridine as indicated. Green boxes indicate promoters with desirable traits of strict nitrate inducibility. c Schematic overview of spotting pattern of strains containing the indicated stc promoter driving pyrG on the plates depicted in panel (b). Bold letters indicate stc promoters with desired traits of nitrate inducibility. Cntr is the control strain TPMW7.2. $\mathbf{d}$ Northern blot analysis of all sterigmatocystin cluster genes from the A. nidulans WT and a $\triangle a f R$ knock-out mutant. Strains were grown in duplicate under sterigmatocystin production conditions (in $50 \mathrm{~mL}$ of GMM at $37^{\circ}$ for $48 \mathrm{~h}$ at $250 \mathrm{rpm}$ ) before RNA extraction. Probes for indicated genes were hybridized and rRNA was visualized as loading control 
promoters, we grew them on media containing either nitrate (induces aflR/S expression; Fig. 1b) or ammonium, and supplemented with or without uracil/uridine (Fig. 2b, c). The growth assay showed that eight of the tested promoters (stcA, stcB, stcI, stcM, stcN, stcQ, stcV, and $s t c W$ ) exhibited the desired ability to grow on plates without uracil/uridine supplementation on nitrate containing media only (Fig. 2b, c), demonstrating specific expression under induction conditions. Three of the promoters tested exhibited leaky expression $(s t c C$, $s t c D$, and $s t c E$ ) as we observed colony growth of strains on media containing ammonium (Fig. 2b, c) where aflR/S should not be induced (Fig. 1b). In order to confirm control of the identified promoters by AflR, we investigated expression of all stc cluster genes in an A. nidulans WT and an isogenic $\Delta a f l R$ knock-out strain [56] under sterigmatocystin production conditions. We found that in addition to the eight promoters identified in our plate assay, most of the remaining cluster genes were also expressed in an AflR-dependent manner (Fig. 2d). We speculate that either the length of the chosen promoters, the difference in culture conditions, or the insufficient expression level could be responsible for the observed discrepancies of $s t c$ activation of the AfpyrG reporter gene.

To test the functionality of our expression system genes responsible for carotenoid production from Fusarium fujikuroi [2-4] were expressed in our A. nidulans nitrate-inducible aflR/S strain TPMW2.3. In F. fujikuroi, the geranylgeranyl diphosphate (GGDP) synthase gene ggs1 is responsible for production of GGDP [34], which is a substrate for CarRA and CarB, encoded by two of the clustered carotenoid biosynthetic genes needed for $\beta$-carotene production [31]. We inserted the ggs1 gene driven by the $s t c M$ promoter and $0.5 \mathrm{~kb}$ of the native terminator, a riboflavin selectable marker flanked by the $y A$ border regions (Additional file 1: Table S3; Additional file 2: Fig. S3), and the two carotenoid cluster genes $\operatorname{carR} A$ and $\operatorname{car} B$ including $0.5 \mathrm{~kb}$ of the native terminator regions, responsible for $\beta$-carotene production [31] under control of the bidirectional $s t c A / B$ promoter flanked by the $w A$ border regions (Additional file 1: Table S3; Additional file 2: Fig. S3). Both plasmids were linearized and transformed into TPMW2.3 consecutively, yielding strain TJSF3.1 (Fig. 3a; Additional file 1: Table S1; Additional file 2: Fig. S4). Nitrate-inducible expression of ggs1, carRA, and carB was confirmed by northern blot analysis compared to a prototroph control strain that produced white spores (TPMW8.2) (Fig. 3b). When the two strains were grown on nitrate containing media, TJSF3.1 exhibited a characteristic orange color that was absent in the control (Fig. 3c). Characterization of carotene production by HPLC showed that the strain TJSF3.1 produced $125 \mu \mathrm{g} \beta$-carotene per gram mycelial dry weight in our experimental setting (Fig. 3d, e). The production of $\beta$-carotene was significantly higher on nitrate induction media than on non-induction media containing glutamine (Fig. 3d, e). The control strain TPMW8.2 did not show any carotene production (Fig. 3d).

As carotenoid production in N. crassa and Fusarium spp. occurs in both mycelia and spores [5], we asked whether a similar distribution would occur in our production strain. Therefore, mycelia and spores were assessed individually for $\beta$-carotene content. Carotenoids were only produced in the mycelia and not in the spores (Fig. 4a). Since the GGDP produce by Ggs1 is also utilized for ergosterol production in F. fujikuroi [34] we set out to investigate if the homolog of $g g s 1$ in $A$. nidulans (AN0654, 54\% identity, $e$-value: $4.0^{-118}$ ) would be sufficient for $\beta$-carotene production. A strain was constructed that only expressed $\operatorname{carR} A$ and $\operatorname{car} B$ called TJSF1.1 (Additional file 2: Fig. S4). When carotenoid production between TJSF1.1 ( $\operatorname{carRA}$ and $\operatorname{car} B$ ) and TJSF3.1 (ggs1, carRA, and carB) was compared no significant difference under inducing conditions was observed (Fig. 4b), suggesting that AN0654 is sufficient to provide the maximum amount of GGDP that can be funneled into carotenoid production. As it is known that one of the bottlenecks during carotenogenesis is the production of mevalonate (a GGDP precursor) by the 3-hydroxyl-3-methyl-glutaryl-conenzyme A reductase (HMG CoA reductase) [1], we grew the two production strains on nitrate media supplemented with mevalonate before carotenoid quantification. However, we did not find any difference in production levels between the strains grown with or without mevalonate (Fig. 4c).

\section{Discussion}

Many efforts have been made to increase expression of fungal natural products $[6,35]$. Apart from increasing production in the native host, a major focus has been on developing heterologous expression systems. Heterologous systems have the advantage that they can be carried out in a safe host system without toxic byproducts, that is easily amenable to genetic manipulation and preferably inducible [50]. Traditional approaches are laborious as they are mainly based on over-expressing each natural product cluster individually or sequentially, thereby relying on multiple selection markers that limit the number of genes expressed and subsequently reduce the chemical complexity of the natural product produced [55]. There have been successful reports on marker recycling to overcome this issue $[14,38]$, but these approaches involve multiple time-consuming transformation steps. Additionally, construction of the expression plasmids or cassettes has been achieved by labor intensive restriction enzyme- or fusion PCR-mediated methods [22, 25]. 


\section{a \\ AfIS \\ TJSF3.1 (R/S) \\ AfIR}

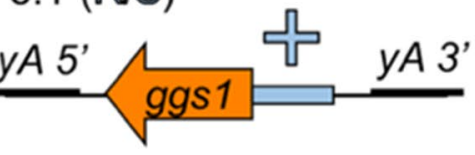

b
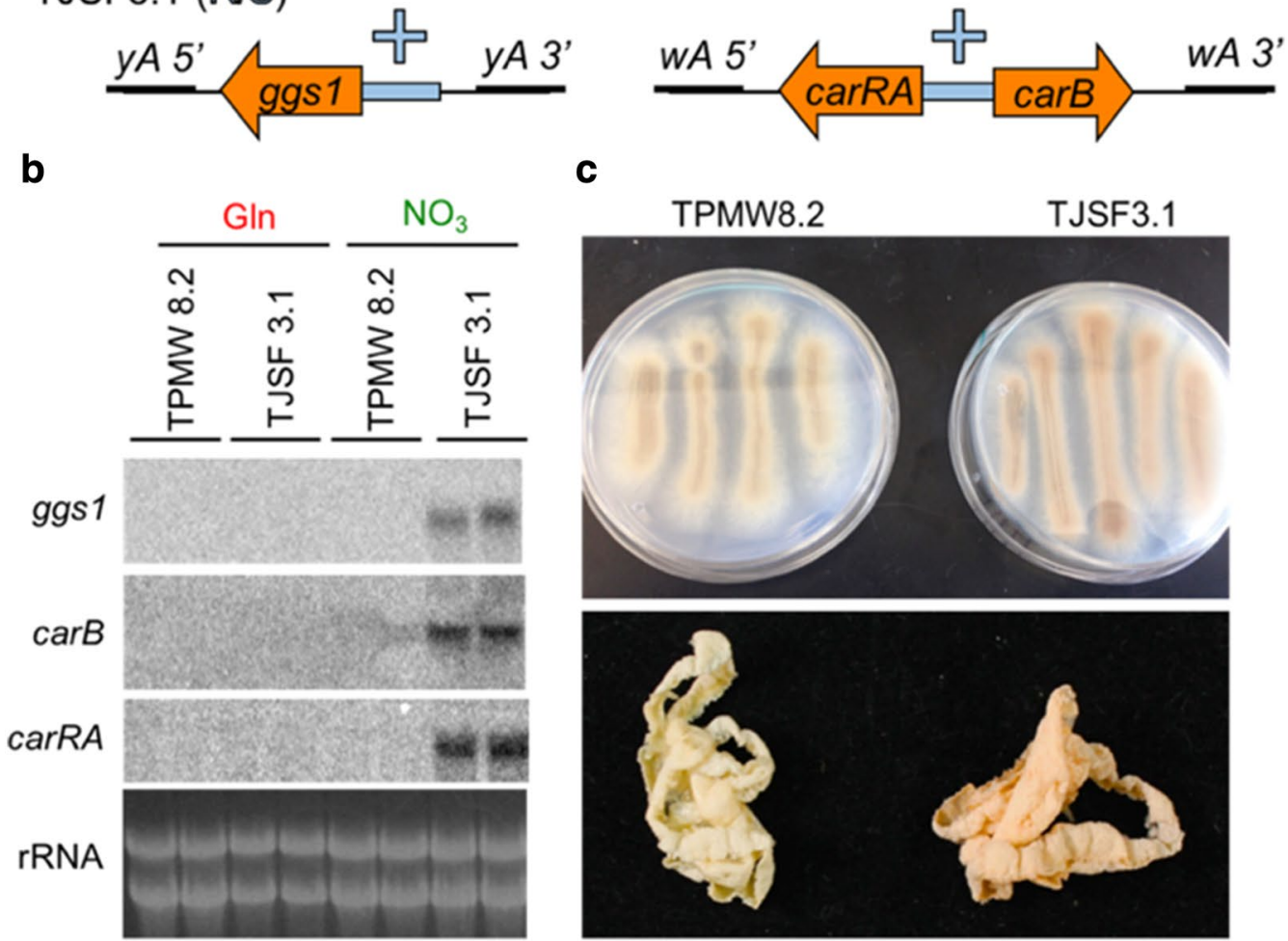

C
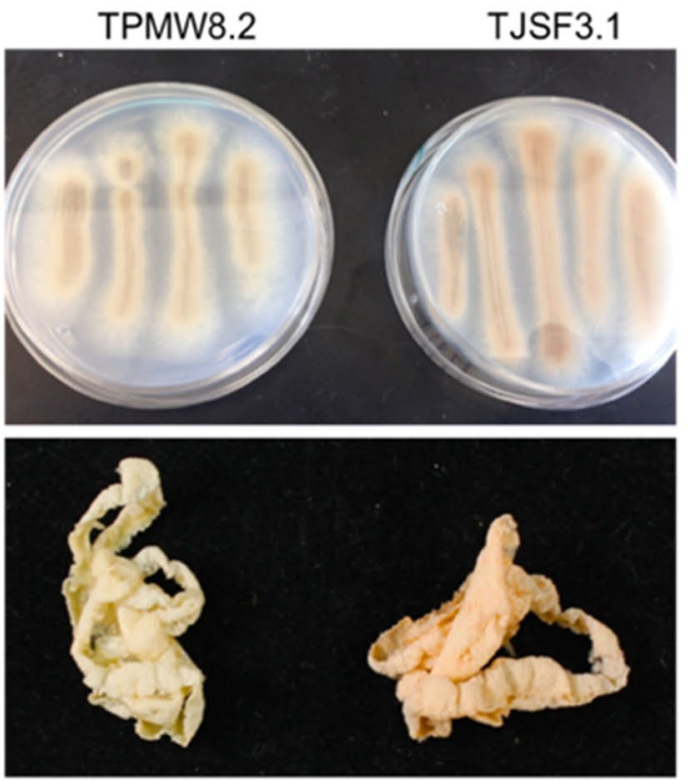

d

$453 \mathrm{~nm}$

e
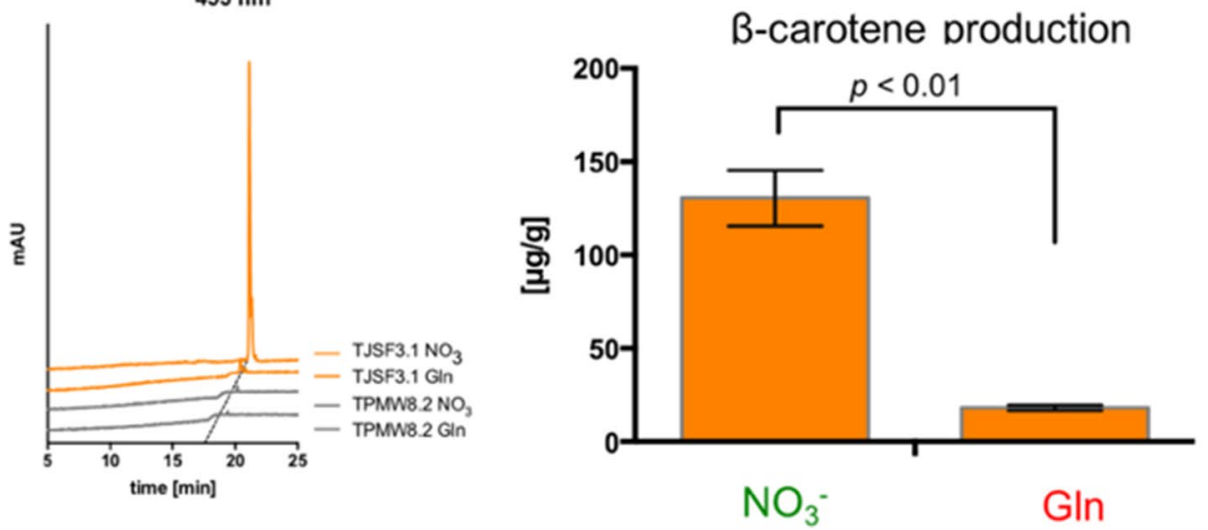

Fig. 3 Nitrate-dependent $\beta$-carotene production in A. nidulans. a Schematic overview of A. nidulans carotenoid production strain TJSF3.1 that harbors the stcM-driven F. fujikuroi ggs 1 gene at the $y A$ locus and the stcA/B-driven F. fujikuroi carRA/B genes at the wA locus. b Northern blot expression analysis of indicated genes in the indicated strains. The strains were grown in duplicate for $24 \mathrm{~h}$ in $50 \mathrm{~mL}$ of GMM with $35 \mathrm{mM}$ glutamine (Gln) as nitrogen source for $24 \mathrm{~h}$ at $250 \mathrm{rpm}$ at $37^{\circ} \mathrm{C}$. The mycelia were washed and shifted into new media containing either $\mathrm{Gln}_{\mathrm{n}}$ or $\mathrm{NO}_{3}{ }^{-}$as nitrogen sources and grown at $250 \mathrm{rpm}$ and $37^{\circ} \mathrm{C}$ for $1 \mathrm{~h}$ before RNA extraction. RNA was visualized as loading control. c Growth on solid medium demonstrating carotene expression from strain TJSF3.1 and control strain TPMW8.2 grown for $72 \mathrm{~h}$ at $37^{\circ} \mathrm{C}$ on solidified GMM media containing nitrate as nitrogen source. Bottom picture shows mycelia of the same strains collected from liquid stationary GMM media containing nitrate as nitrogen source grown for $72 \mathrm{~h}$ at $37^{\circ} \mathrm{C}$. d HPLC chromatograms at $453 \mathrm{~nm}$ of $\beta$-carotene extracted from indicate strains grown as described in panel (c). e Quantification of $\beta$-carotene produced by TJSF3.1 grown on either $\mathrm{NO}_{3}{ }^{-}$or glutamine (GIn) 

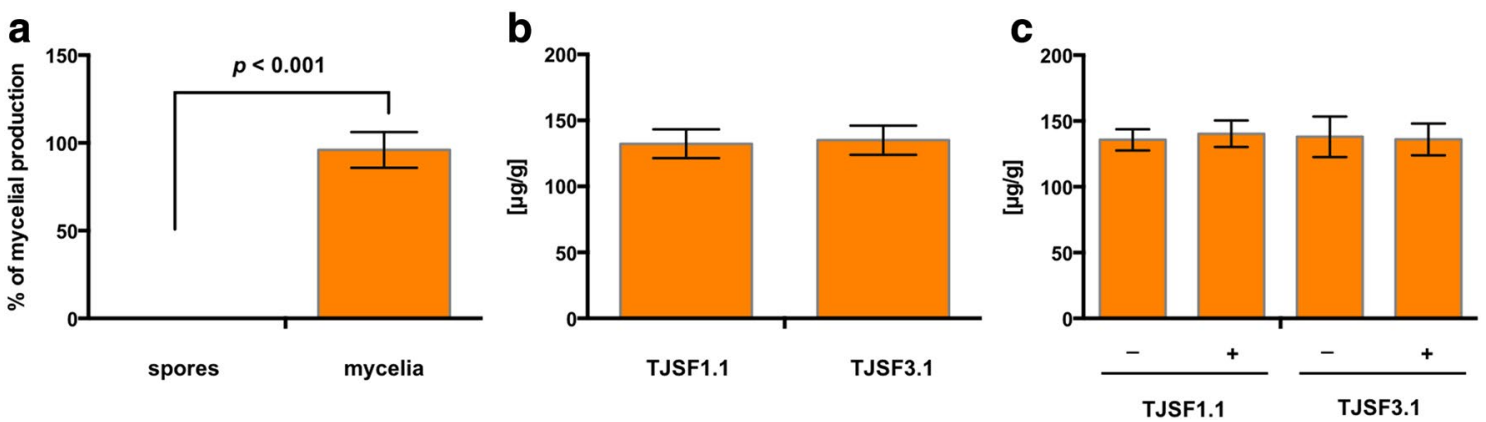

Fig. 4 Tissue- and media-specific $\beta$-carotene production. a Comparison of $\beta$-carotene production in spores and mycelia of TJSF3.1 in triplicates. The strains were grown under nitrate inducing conditions and carotenoid production was normalized to the amount produced in mycelia. $\mathbf{b}$ Comparison of $\beta$-carotenoid production between TJSF1.1 (carRA and carB) and TJSF3.1 (ggs1, carRA and carB). Strains were grown under nitrate inducible conditions and $\beta$-carotene was quantified based on normalized dry weight in triplicates. No significant difference be could be detected. c Comparison of $\beta$-carotene production between TJSf1.1 (carRA and carB) and TJSF3.1 (ggs1, carRA and carB) grown on nitrate inducible conditions either supplemented with (+) or without $(-) 10 \mathrm{mM}$ mevalonate in triplicates. No significant difference be could be detected

The ease of yeast recombinational cloning [39] has been exploited for a wide range of molecular methods, including gene knock-out libraries [17] and expression systems [47] in filamentous fungi as well as yeast itself [8]. Technically, yeast recombinational cloning allows for the assembly of multiple PCR fragments up to a vector size of several ten thousand kilo bases [39]. One of the major hurdles to overcome during yeast recombineering, is undesired recombination among multiple identical DNA regions. Recently, a study in A. terreus demonstrated the requirement of an AflR-like transcription factor, TerR, for expression of all twelve terrein cluster genes [24] similar to our expression data for AflR-dependency of all 25 stc genes. The system was subsequently used to control one of the terrein promoters in a heterologous expression system in $A$. niger to demonstrate activation of ors $A$ from $A$. nidulans [24]. Here, we have demonstrated the specific induction of eight of the $25 \mathrm{stc}$ promoters to control the expression of a reporter gene (pyrG). Subsequently, we have utilized three of the eight promoters to successfully express three Fusarium spp. derived genes responsible for carotenoid production in A. nidulans and confirm functionality of their gene products by detection of $\beta$-carotene.

As a precursor of vitamin A, $\beta$-carotene has long been in the focus of biotechnology. The most prominent example of heterologous gene expression leading to the production of $\beta$-carotene is the development of Golden Rice by Monsanto [37]. However, $\beta$-carotenoid production was also achieved in baker's yeast and bacteria. The amounts of carotenoids produced by the production strain constructed in this study are equivalent to the first production strain engineered in yeast [52]. Recent advances in manipulating metabolic pathways and genetic elements have increased the production in baker's yeast $[8,30]$, and similar approaches could be undertaken to increase production in A. nidulans.

Notably, production of $\beta$-carotene is restricted to the mycelia in the $A$. nidulans production strains investigated in this study, whereas in other fungal species like Neurospora crassa and F. fujikuroi, carotenes are predominantly produced in asexual spores $[26,31]$. One explanation might be the developmentally controlled expression pattern of the niaD promoter, as it was shown to be only transiently expressed at early stages of conidiation, but not at later time points [33]. Sterigmatocystin and aflatoxin in Aspergillus species are predominantly found in the mycelial fraction and a complex fusion network of vesicles containing different precursors and biosynthetic enzymes that ensure correct cellular localization of these secondary metabolites is being unveiled by several studies [32, 42, 49]. Additionally, pioneering work in A. fumigatus has demonstrated that certain natural products are predominantly produced in the asexual spores (conidia) $[27,29]$. These findings suggest that conidial directed cellular pathways in the native host (Fusarium) may differ significantly from Aspergillus as location of $\beta$-carotene is not the same in the native and heterologous host. Determining which factors control the direction of fungal natural products to certain developmental structures in different fungal species will be a fascinating future task.

\section{Conclusions}

This study presents a new heterologous expression system for fungal natural products in the genetic model organism $A$. nidulans. The system described here makes use of the ability to co-express, minimally, eight promoters by a fungal-specific $\mathrm{Zn}(\mathrm{II})_{2} \mathrm{Cys}_{6}$ transcription factor, AflR, and its cofactor AflS. By replacing the intrinsic bidirectional $a f l R / S$ promoter with a nitrate bidirectional 
inducible promoter, all eight identified genes can be simultaneously activated and repressed. As all eight identified promoters differ in their DNA sequence, the system has the potential to utilize one-step yeast recombinational cloning for assembly of entire secondary metabolite gene clusters. Here, we demonstrate the production of $\beta$-carotene by heterologous expression of three genes from F. fujikuroi. The inducibility of the system also is useful for production of toxic metabolites at a stage when the host strain has accumulated a significant biomass.

\section{Additional files}

Additional file 1. Additional tables.

Additional file 2. Additional figures.

\section{Abbreviations}

SM: secondary metabolite; FDA: Food and Drug Administration; ST: sterigmatocystin.

\section{Authors' contributions}

PW, AAS, and NPK conceived and designed the experiments. PW, AAS, JSF, PMW, and AN performed the experiments. NPK provided reagents and materials. PW, AAS, and NPK wrote the manuscript. All authors read and approved the final manuscript.

\section{Author details}

${ }^{1}$ Department of Medical Microbiology and Immunology, University of Wisconsin, Madison, WI 53706, USA. ${ }^{2}$ Department of Bacteriology, University of Wisconsin, Madison, WI 53706, USA. ${ }^{3}$ Present Address: Hexagon Bio, Menlo Park, CA 94025, USA. ${ }^{4}$ Present Address: Department of Cell and Regenerative Biology, University of Wisconsin, Madison, WI 53705, USA. ${ }^{5}$ Present Address: Davis Genome Center - Metabolomics, University of California, 451 Health Science Drive, Davis, CA 95616, USA. ${ }^{6}$ Present Address: Ocean College, Zhejiang University, Hangzhou 310058, Zhejiang Province, People's Republic of China.

\section{Acknowledgements}

The authors would like to thank Jacob Hagen for excellent technical assistance.

\section{Competing interests}

The expression system described in this study has been filed as patent in the United States under Number P150029US01 entitled "Methods and Systems for Producing Fungal Secondary Metabolites" for the Wisconsin Alumni Research Foundation (WARF).

\section{Availability of data and materials}

All data generated and analyzed during this study are included in this published article [and its supplementary information files].

\section{Consent for publication}

Not applicable.

\section{Ethics approval and consent to participate}

Not applicable.

\section{Funding}

This work was funded by the Draper Technology Innovation Fund (TIF) from the University of Wisconsin-Madison to PW and NPK and by funds from AgriMetis, LLC to AAS and NPK. PMW was supported by Grant NSF No. 41406141 from the National Science Foundation. AAS was sponsored by the Genetics Training Program, NIH GM07133, from the University of Wisconsin-Madison.

\section{Publisher's Note}

Springer Nature remains neutral with regard to jurisdictional claims in published maps and institutional affiliations.

Received: 21 December 2017 Accepted: 5 March 2018

Published online: 13 March 2018

\section{References}

1. Albermann S, Linnemannstöns P, Tudzynski B. Strategies for strain improvement in Fusarium fujikuroi: overexpression and localization of key enzymes of the isoprenoid pathway and their impact on gibberellin biosynthesis. Appl Microbiol Biotechnol. 2013;97:2979-95.

2. Avalos J, Carmen Limón M. Biological roles of fungal carotenoids. Curr Genet. 2015;61:309-24.

3. Avalos J, Estrada AF. Regulation by light in Fusarium. Fungal Genet Biol. 2010;47:930-8

4. Avalos J, Prado-Cabrero A, Estrada AF. Neurosporaxanthin production by Neurospora and Fusarium. Methods Mol Biol. 2012;898:263-74.

5. Baima S, Carattoli A, Macino G, Morelli G. Photoinduction of albino-3 gene expression in Neurospora crassa conidia. J Photochem Photobiol B. 1992:15:233-8

6. Boecker S, Zobel S, Meyer V, Süssmuth RD. Rational biosynthetic approaches for the production of new-to-nature compounds in fungi. Fungal Genet Biol. 2016;89:89-101.

7. Bok JW, Soukup AA, Chadwick E, Chiang YM, Wang CC, Keller NP. VeA and MvIA repression of the cryptic orsellinic acid gene cluster in Aspergillus nidulans involves histone 3 acetylation. Mol Microbiol. 2013;89:963-74.

8. Bond C, Tang Y, Li L. Saccharomyces cerevisiae as a tool for mining, studying and engineering fungal polyketide synthases. Fungal Genet Biol. 2016;89:52-61.

9. Brown DW, Yu JH, Kelkar HS, Fernandes M, Nesbitt TC, Keller NP, Adams TH, Leonard TJ. Twenty-five coregulated transcripts define a sterigmatocystin gene cluster in Aspergillus nidulans. Proc Natl Acad Sci USA. 1996;93:1418-22

10. Burger G, Tilburn J, Scazzocchio C. Molecular cloning and functional characterization of the pathway-specific regulatory gene nirA, which controls nitrate assimilation in Aspergillus nidulans. Mol Cell Biol. 1991;11:795-802.

11. Butchko RA, Brown DW, Busman M, Tudzynski B, Wiemann P. Lae1 regulates expression of multiple secondary metabolite gene clusters in Fusarium verticillioides. Fungal Genet Biol. 2012;49:602-12.

12. Carberry S, Molloy E, Hammel S, O'Keeffe G, Jones GW, Kavanagh K, Doyle S. Gliotoxin effects on fungal growth: mechanisms and exploitation. Fungal Genet Biol. 2012;49:302-12.

13. Chiang YM, Szewczyk E, Davidson AD, Keller N, Oakley BR, Wang CC. A gene cluster containing two fungal polyketide synthases encodes the biosynthetic pathway for a polyketide, asperfuranone, in Aspergillus nidulans. J Am Chem Soc. 2009;131:2965-70.

14. Chiang YM, Oakley CE, Ahuja M, Entwistle R, Schultz A, Chang SL, Sung $C T$, Wang CC, Oakley BR. An efficient system for heterologous expression of secondary metabolite genes in Aspergillus nidulans. J Am Chem Soc. 2013;135:7720-31.

15. Chiang YM, Ahuja M, Oakley CE, Entwistle R, Asokan A, Zutz C, Wang CC, Oakley BR. Development of genetic dereplication strains in Aspergillus nidulans results in the discovery of Aspercryptin. Angew Chem Int Ed Engl. 2016;55:1662-5.

16. Clardy J, Walsh C. Lessons from natural molecules. Nature 2004;432:829-37.

17. Colot HV, Park G, Turner GE, Ringelberg C, Crew CM, Litvinkova L, Weiss RL, Borkovich KA, Dunlap JC. A high-throughput gene knockout procedure for Neurospora reveals functions for multiple transcription factors. Proc Natl Acad Sci USA. 2006;103:10352-7.

18. Díaz-Sánchez V, Estrada AF, Trautmann D, Al-Babili S, Avalos J. The gene carD encodes the aldehyde dehydrogenase responsible for neurosporaxanthin biosynthesis in Fusarium fujikuroi. FEBS J. 2011;278:3164-76.

19. Díaz-Sánchez V, Limón MC, Schaub P, Al-Babili S, Avalos J. A RALDH-like enzyme involved in Fusarium verticillioides development. Fungal Genet Biol. 2016;86:20-32. 
20. Ehrlich KC. Predicted roles of the uncharacterized clustered genes in aflatoxin biosynthesis. Toxins (Basel). 2009;1:37-58.

21. Fernandes M, Keller NP, Adams TH. Sequence-specific binding by Aspergillus nidulans AfR, a C6 zinc cluster protein regulating mycotoxin biosynthesis. Mol Microbiol. 1998;28:1355-65.

22. Fujii I, Ono Y, Tada H, Gomi K, Ebizuka Y, Sankawa U. Cloning of the polyketide synthase gene at $X$ from Aspergillus terreus and its identification as the 6-methylsalicylic acid synthase gene by heterologous expression. Mol Gen Genet. 1996;253:1-10.

23. Green MR, Sambrook J. Molecular cloning: a laboratory manual. Cold Spring Harbor: Cold Spring Harbor Laboratory Press; 2012.

24. Gressler M, Hortschansky P, Geib E, Brock M. A new high-performance heterologous fungal expression system based on regulatory elements from the Aspergillus terreus terrein gene cluster. Front Microbiol. 2015:6:184.

25. Kealey JT, Liu L, Santi DV, Betlach MC, Barr PJ. Production of a polyketide natural product in nonpolyketide-producing prokaryotic and eukaryotic hosts. Proc Natl Acad Sci USA. 1998:95:505-9.

26. Li C, Schmidhauser TJ. Developmental and photoregulation of $a l-1$ and al-2, structural genes for two enzymes essential for carotenoid biosynthesis in Neurospora. Dev Biol. 1995;169:90-5.

27. Lim FY, Keller NP. Spatial and temporal control of fungal natural product synthesis. Nat Prod Rep. 2014;31:1277-86.

28. Lim FY, Hou Y, Chen Y, Oh JH, Lee I, Bugni TS, Keller NP. Genome-based cluster deletion reveals an endocrocin biosynthetic pathway in Aspergillus fumigatus. Appl Environ Microbiol. 2012;78:4117-25.

29. Lim FY, Ames B, Walsh CT, Keller NP. Co-ordination between BrlA regulation and secretion of the oxidoreductase FmqD directs selective accumulation of fumiquinazoline $C$ to conidial tissues in Aspergillus fumigatus. Cell Microbiol. 2014;16:1267-83.

30. Lin YJ, Chang JJ, Lin HY, Thia C, Kao YY, Huang CC, Li WH. Metabolic engineering a yeast to produce astaxanthin. Bioresour Technol. 2017;245:899-905.

31. Linnemannstöns P, Prado MM, Fernández-Martín R, Tudzynski B, Avalos J. A carotenoid biosynthesis gene cluster in Fusarium fujikuroi: the genes carB and carRA. Mol Genet Genomics. 2002;267:593-602.

32. Linz JE, Chanda A, Hong SY, Whitten DA, Wilkerson C, Roze LV. Proteomic and biochemical evidence support a role for transport vesicles and endosomes in stress response and secondary metabolism in Aspergillus parasiticus. J Proteome Res. 2012;11:767-75.

33. Marcos AT, Ramos MS, Marcos JF, Carmona L, Strauss J, Cánovas D. Nitric oxide synthesis by nitrate reductase is regulated during development in Aspergillus. Mol Microbiol. 2016;99:15-33.

34. Mende K, Homann V, Tudzynski B. The geranylgeranyl diphosphate synthase gene of Gibberella fujikuroi: isolation and expression. Mol Gen Genet. 1997:255:96-105.

35. Meyer V, Nevoigt E, Wiemann P. The art of design. Fungal Genet Biol. 2016;89:1-2.

36. Newman DJ, Cragg GM. Natural products as sources of new drugs over the 30 years from 1981 to 2010. J Nat Prod. 2012;75:311-35.

37. Normile D. Agricultural biotechnology. Monsanto donates its share of golden rice. Science. 2000;289:843-5.

38. Oakley CE, Ahuja M, Sun WW, Entwistle R, Akashi T, Yaegashi J, Guo CJ, Cerqueira GC, Russo Wortman J, Wang CC, Chiang YM, Oakley BR. Discovery of McrA, a master regulator of Aspergillus secondary metabolism. Mol Microbiol. 2017;103:347-65.

39. Oldenburg KR, Vo KT, Michaelis S, Paddon C. Recombination-mediated PCR-directed plasmid construction in vivo in yeast. Nucleic Acids Res. 1997;25:451-2.

40. Palmer JM, Perrin RM, Dagenais TR, Keller NP. H3K9 methylation regulates growth and development in Aspergillus fumigatus. Eukaryot Cell. 2008; 7:2052-60

41. Peláez F. The historical delivery of antibiotics from microbial natural products—can history repeat. Biochem Pharmacol. 2006;71:981-90,

42. Pfannenstiel BT, Zhao X, Wortman J, Wiemann P, Throckmorton K, Spraker JE, Soukup AA, Luo X, Lindner DL, Lim FY, Knox BP, Haas B, Fischer GJ, Choera T, Butchko RAE, Bok JW, Affeldt KJ, Keller NP, Palmer JM. Revitalization of a forward genetic screen identifies three new regulators of fungal secondary metabolism in the genus Aspergillus. MBio. 2017;8:e01246-17.
43. Porquier A, Morgant G, Moraga J, Dalmais B, Luyten I, Simon A, Pradier JM, Amselem J, Collado IG, Viaud M. The botrydial biosynthetic gene cluster of Botrytis cinerea displays a bipartite genomic structure and is positively regulated by the putative $\mathrm{Zn}(\mathrm{II}) 2 \mathrm{Cys} 6$ transcription factor BcBot6. Fungal Genet Biol. 2016;96:33-46.

44. Punt PJ, Greaves PA, Kuyvenhoven A, van Deutekom JC, Kinghorn JR, Pouwels PH, van den Hondel CA. A twin-reporter vector for simultaneous analysis of expression signals of divergently transcribed, contiguous genes in filamentous fungi. Gene. 1991;104:119-22.

45. Punt PJ, Strauss J, Smit R, Kinghorn JR, van den Hondel CA, Scazzocchio C. The intergenic region between the divergently transcribed niiA and niaD genes of Aspergillus nidulans contains multiple NirA binding sites which act bidirectionally. Mol Cell Biol. 1995;15:5688-99.

46. Qiao J, Kontoyiannis DP, Wan Z, Li R, Liu W. Antifungal activity of statins against Aspergillus species. Med Mycol. 2007;45:589-93.

47. Schumacher J. Tools for Botrytis cinerea: New expression vectors make the gray mold fungus more accessible to cell biology approaches. Fungal Genet Biol. 2012:49:483-97.

48. Shimizu K, Keller NP. Genetic involvement of a cAMP-dependent protein kinase in a $\mathrm{G}$ protein signaling pathway regulating morphological and chemical transitions in Aspergillus nidulans. Genetics. 2001;157:591-600.

49. Soukup AA, Fischer GJ, Luo J, Keller NP. The Aspergillus nidulans Pbp1 homolog is required for normal sexual development and secondary metabolism. Fungal Genet Biol. 2017;100:13-21.

50. Sun WW, Guo CJ, Wang CCC. Characterization of the product of a nonribosomal peptide synthetase-like (NRPS-like) gene using the doxycycline dependent Tet-on system in Aspergillus terreus. Fungal Genet Biol. 2016;89:84-8.

51. Wiemann P, Keller NP. Strategies for mining fungal natural products. J Ind Microbiol Biotechnol. 2013;41:301-13.

52. Yamano S, Ishii T, Nakagawa M, Ikenaga H, Misawa N. Metabolic engineering for production of beta-carotene and lycopene in Saccharomyces cerevisiae. Biosci Biotechnol Biochem. 1994;58:1112-4.

53. Yeh HH, Ahuja M, Chiang YM, Oakley CE, Moore S, Yoon O, Hajovsky H, Bok JW, Keller NP, Wang CC, Oakley BR. Resistance gene-guided genome mining: Serial promoter exchanges in Aspergillus nidulans reveal the biosynthetic pathway for fellutamide B, a proteasome inhibitor. ACS Chem Biol. 2016;11:2275-84.

54. Yin WB, Baccile JA, Bok JW, Chen Y, Keller NP, Schroeder FC. A nonribosomal peptide synthetase-derived iron(III) complex from the pathogenic fungus Aspergillus fumigatus. J Am Chem Soc. 2013;135:2064-7.

55. Yin WB, Chooi YH, Smith AR, Cacho RA, Hu Y, White TC, Tang Y. Discovery of cryptic polyketide metabolites from dermatophytes using heterologous expression in Aspergillus nidulans. ACS Synth Biol. 2013;29:549-55.

56. Yu JH, Butchko RA, Fernandes M, Keller NP, Leonard TJ, Adams TH. Conservation of structure and function of the aflatoxin regulatory gene aflR from Aspergillus nidulans and A. flavus. Curr Genet. 1996;29:549-55.

57. Zhang P, Wang X, Fan A, Zheng Y, Liu X, Wang S, Zou H, Oakley BR, Keller NP, Yin WB. A cryptic pigment biosynthetic pathway uncovered by heterologous expression is essential for conidial development in Pestalotiopsis fici. Mol Microbiol. 2017;105:469-83.

\section{Submit your next manuscript to BioMed Central and we will help you at every step:}

- We accept pre-submission inquiries

- Our selector tool helps you to find the most relevant journal

- We provide round the clock customer support

- Convenient online submission

- Thorough peer review

- Inclusion in PubMed and all major indexing services

- Maximum visibility for your research

Submit your manuscript at www.biomedcentral.com/submit 